\title{
A pensar uma proposta pedagógica na escola: crianças e o protagonismo infantil
}

\begin{abstract}
Resumo: Construiu-se este artigo a partir da discussão sobre o protagonismo infantil em uma escola pública, cuja proposta pedagógica intensificou-se a partir do desafio lançado aos seus professores. A investigação tomou por cenário uma Escola Municipal de Educação Infantil, do Vale do Taquari/RS/Brasil, e analisou uma proposta de ensino que tem como base potencializadora, a valorização do protagonismo infantil. Metodologicamente, teceu-se de uma concepção qualitativa, de tipo etnográfica, que se produziu pela observação participante. Aproximamo-nos de crianças na faixa etária de quatro a cinco anos de idade e mostramos a voz de cinco professoras, que responderam sobre suas práticas e a elaboração do planejamento diário, relatando o surgimento do projeto sobre o protagonismo infantil, o ensino e as contribuições da proposta na aprendizagem das crianças. Foi possível constatar neste estudo que o propósito da metodologia dessa Instituição voltada ao enfoque emergente é priorizar a criança como protagonista de sua aprendizagem, proporcionando atividades, projetos, brincadeiras, voltadas ao seu interesse e necessidades frente aos diferentes contextos em que vivem. Os professores, pais, crianças e comunidade escolar, visam, dentro do possível, discutir e analisar minuciosamente a pedagogia oferecida pela Escola, para assim melhor atender a demanda que se apresenta e projetar a educação na qual acreditam.
\end{abstract}

Palavras chaves: Protagonismo infantil. Planejamento didático-pedagógico. Espaços na Educação Infantil. Docência na Educação Infantil.

\section{Abrindo as portas da escola}

A criança se constitui através de sua interação e relação estabelecida pelos diferentes grupos em seu meio social. Ao ingressar na Educação Infantil, além do contato com a família, a criança conhecerá e irá se relacionar com um universo social farto de interações que a levará a ampliar seus conhecimentos a respeito de si e dos outros. Este artigo discute tais relações e põe-se a apresentar o Protagonismo Infantil em uma Escola de Educação Infantil, que se preocupa em priorizar os espaços para uma educação na qual os envolvidos acreditam e trabalham por ela.

A Eđucação Básica oferecida em creches e pré-escolas, não somente no Brasil, mas na América Latina, ganhou espaço dado ao alto índice de crescimento da urbanização nas cidades. Daí emergiu a necessidade da mulher também intervir no mercado de trabalho, a fim de auxiliar nos suprimentos das despesas familiares (ABRAMOWICZ, 2003) - o que também provocou uma grande preocupação em relação ao cuidado e educação de seus filhos, pois, muitas vezes, não havia com quem deixá-los durante
Carine Rozane Steffens Universidade do Vale do Taquari (Univates)

carinesteffens@gmail.com

Tania Micheline Miorando Universidade do Vale do Taquari (Univates)

tmiorando@gmail.com 
o período que não estivesse com eles. A partir daí, começa-se a pensar em Escolas de Educação Infantil e um currículo próprio para o atendimento das crianças, desde sua primeira infância.

No início da institucionalização, as Escolas tinham uma visão assistencialista e de custódia. Porém, a partir de 1990, no Brasil, as creches começaram a ser reconhecidas como um espaço onde se buscava priorizar tanto o cuidar, quanto o educar. As Escolas envolvidas com a educação na primeira infância começaram a conquistar os seus valores, tornando-se ambientes que, além de prezar pelo bem-estar da criança, passaram a adotar uma educação pedagógica voltada ao desenvolvimento da inteligência e dos bons costumes do indivíduo. (KUHLMANN, 1998)

O propósito que se instituía com este novo olhar para a educação de crianças ia além do cuidar ou de manter a criança sob o olhar de um adulto. Traçava-se o esboço de propostas pedagógicas voltadas para uma educação em que a criança passasse a ser mais acreditada em seus conhecimentos. Através da vivência proporcionada em tempos e horários que estava na escola, enriquecia-se por ter oportunidades de ensaiar-se em experiências criativas, lúdicas e acompanhadas, durante o tempo de convívio entre os professores e os colegas.

Esses anos experimentais instigaram a formação de professores que se voltavam a conhecer mais sobre a infância e suas potencialidades. A Educação Infantil, com os professores que escolhiam atuar sua docência com as crianças pequenas, segundo as Diretrizes Curriculares Nacionais para a Educação Infantil - DCNEI (BRASIL, 2010, p. 7), "[...] vive um intenso processo de revisão de concepções sobre educação de crianças em espaços coletivos, e de seleção e fortalecimento de práticas pedagógicas mediadoras de aprendizagens e do desenvolvimento das crianças". Nota-se que um olhar mais atento surge no campo da Educação Infantil para melhor atender a demanda de crianças que chegam às escolas.

Dos movimentos primevos na Educação Infantil, passadas algumas décadas, entramos em tempos com novas concepções: a criança é reconhecida como um ser histórico e dotado de direitos. Por meio disso, acredita-se que as Propostas Pedagógicas da Educação Infantil devam ser focadas nas crianças, assim como sugerem as DCNEI. (BRASIL, 2010, p. 18) As Escolas passam a garantir a função sociopolítica e pedagógica (BRASIL, 2010), respeitando a autonomia das crianças, suas diferentes culturas, identidades e singularidades, proporcionando a liberdade de expressão e o 
reforço à criatividade através da ludicidade em suas diferentes manifestações artísticas e culturais.

A Escola também é espaço de segurança, garantindo o direito "[...] à proteção, à saúde, à liberdade, à confiança, ao respeito, à dignidade, à brincadeira, à convivência e à interação com outras crianças". (BRASIL, 2010, p. 19) O professor que a recebe prepara-se para acolhê-la e dedica seu tempo a uma convivência que sai a descobrir como tornar potente as sugestões imaginativas que as crianças trazem de um mundo ainda mais fantástico.

A DCNEI (BRASIL, 2010) e as teorias educacionais sugerem às Escolas de Educação Infantil tornarem-se um ambiente próprio no qual as crianças possam criar vínculos, construir laços de amizade e confiança nas relações com as pessoas com quem convivem diariamente. Passa a ser pauta dos planejamentos e estudos pedagógicos dos professores atividades que se ocupam em potencializar aprendizagens em tempos e espaços lúdicos na Escola. É preciso oferecer às crianças um espaço que seja adequado, cuidado esteticamente para o olhar infantil ao mesmo tempo que oportunize diferentes experiências que correspondam às suas principais necessidades e desejos, garantindo assim, um crescimento saudável.

A seguir, passamos a mostrar a experiência a que fomos oportunizadas a discutir e apresentar neste estudo. Falamos da proposta desta investigação a fim de nos aproximarmos e ampliarmos o foco sobre como as professoras organizam as atividades voltadas ao desafiante compromisso apontado nas Diretrizes, acima citadas: práticas pedagógicas que visam à autonomia da criança e da Escola nos seus fazeres docentes.

\section{Definindo a caminhada}

A proposta metodológica desta investigação está traçada pelos padrões qualitativos em pesquisa, que, na Educação tem marcado um campo importante nos estudos. A pesquisa qualitativa sobressai-se nas investigações realizadas no campo educacional, pois tornam acessíveis variáveis que evidenciam aspectos importantes da investigação (LÜDKE; ANDRÉ, 2013): nossas inquietações e questionamentos puderam ser confrontados ao repertório de saberes que trazemos, abertos a conhecer outros contextos educacionais. A abordagem dos estudos foi investida pelas orientações da Etnografia, ao ver-se em um campo investigativo, cujo objetivo 
estava em focar o estudo no comportamento das pessoas, sua cultura no tempo e num determinado espaço físico. (ANDRÉ, 1994) A observação participante (ANGROSINO, 2009), como uma das possibilidades para o levantamento de informações para os estudos etnográficos, levou-nos a utilizar diversas técnicas de aproximação ao grupo da comunidade escolar e a dispor de diferentes fontes: das observações emergiram anotações e descrições dos fatos, das falas, expressões e a interação com cinco professores que se disponibilizaram a conversar e responder a questionamentos, diretamente ligados à proposta de ensino vigente na Escola. As anotações foram sendo registradas em diário de campo para que, reunidas as informações em seu conjunto, pudessem se abrir em uma análise rica para as discussões.

O tema desta investigação surgiu de problematizações levantadas em aulas do curso de Pedagogia, do Centro Universitário Universidade do Vale do Taquari (Univates) - Lajeado/RS, que pautam o desafio de pensar sobre as práticas educativas relacionadas ao processo de inclusão e possibilidades de apoio e recursos educativos que atendam às necessidades singulares dos alunos da Educação Infantil e anos iniciais. Entre as muitas disciplinas do curso, compreendemos que é na sua totalidade que ampliamos nossa compreensão sobre os contextos escolares e as demandas que apresentam. Assim, os estudantes em formação inicial para a docência saem a buscar na Escola seus temas de investigação a fim de problematizar o que leem e discutem, frente ao que se tem presente nas Escolas em seus municípios de origem.

Instigadas a buscar possibilidades diferentes das já conhecidas, as leituras indicadas (dentre elas, GRAVATÁ, 2013) e os documentários assistidos (Quando sinto que já sei, 2014; Sementes do nosso quintal, 2014), nos levaram a investigar questões que mostrassem diferentes propostas de pedagogias que se evidenciassem àquelas tanto já citadas: o Protagonismo Infantil. Encontramos uma Escola, cuja proposta metodológica se dedica a centrar na criança a participação no planejamento pedagógico diário. Por isso, dedicamos nosso estudo a analisar as práticas realizadas nessa Escola de Educação Infantil, da Rede Municipal, do Vale do Taquari/RS/Brasil.

Já sabíamos que a Escola, ao optar seguir uma proposta que tivesse em sua base potencializadora a valorização do protagonismo infantil, estava provocando em seus professores deslocamentos 
teóricos (DIAS, 2011), que se refletiam no planejamento didático de suas aulas. Pelo consentimento da equipe diretiva, tivemos acesso à leitura das documentações internas da escola: o Regimento Escolar, o Projeto Político Pedagógico e o Projeto Norteador, que foram muito importantes para compreender o discurso no qual se inseria a comunidade escolar e a educação esperada por todos.

Apesar de haver uma gama de autores principalmente no campo da Sociologia e da Antropologia da Infância que abordam e discutem em suas obras sobre o Protagonismo Infantil, o enriquecimento das informações trazidas para o estudo aportou-se em referenciais utilizados para o embasamento teórico sobre o Protagonismo Infantil, dando ênfase à abordagem das Escolas Municipais de Reggio Emilia/Itália, por elas serem fontes de inspiração da prática pedagógica e apresentarem características muito semelhantes a da instituição de ensino escolhida para esta análise. Além da discussão do Protagonismo Infantil, destacamos alguns referenciais que problematizam a Formação de Professores e Políticas Públicas, relacionadas à Educação Infantil.

Os professores mencionaram principalmente sobre a proposta metodológica da Escola, relacionados com os planejamentos diários, realizados com crianças de faixa etária entre quatro e cinco anos de idade. As informações obtidas ganharam forma de categorias de análise e serão apresentadas no decorrer do artigo, garantindo assim, maior visibilidade ao tema abordado neste trabalho. Passamos a conhecê-las.

\section{Os espaços da escola}

A Escola Municipal de Educação Infantil (EMEI) que foi escolhida para analisar a proposta pedagógica, situa-se no Vale do Taquari/RS/Brasil. Esta EMEI foi escolhida por ter uma proposta pedagógica diferente das demais Escolas de Educação Infantil desse Vale. A EMEI tem como sua base potencializadora o Protagonismo Infantil. A instituição foi fundada em 2004 e está localizada em uma área urbana do município. Atualmente suporta uma demanda de cinquenta e três crianças, que variam entre quatro a seis anos de idade. A maioria das crianças são filhas de agricultores, pecuaristas (de pequeno porte), suinocultores e calçadistas.

As crianças estão em quatro turmas, conforme a sua idade. O atendimento é realizado de segunda a sexta-feira, em horário 
integral e parcial. Quanto ao quadro dos profissionais atuantes na Escola, é formado por quinze professores da Educação Infantil, sendo estes efetivos, contratados ou estagiários, com formação inicial no Curso Normal, graduandos ou graduados em Pedagogia. Além destes, a Escola conta com uma equipe de apoio composta por profissionais multidisciplinares: psicopedagoga, psicóloga, fonoaudióloga, nutricionista e dentista.

Apesar da Escola ser mantida pelo município, ainda conta com uma Associação de Pais e Mestres - APM, que tem como objetivo prioritário a integração entre a família, a escola e a comunidade. Sua função é contribuir mensalmente com a gestão da EMEI, a suprir pequenas despesas que são destinadas a passeios e presentes dados às crianças nas datas comemorativas. Além da APM, a instituição conta com o apoio do Conselho Escolar eleito pelos pares, dos diferentes segmentos. Este Conselho é "um órgão de representatividade democrática que visa acompanhar, aconselhar e auxiliar a tomada de decisões da equipe diretiva da escola" (PROJETO POLÍTICO PEDAGÓGICO, 2015, p. 9), dando a conhecer a intenção comunitária que há na gestão da Escola.

Ao ler o Regimento Escolar (2001), o Projeto Político Pedagógico (2015) e o Projeto Norteador (2015) da referida escola - cujo nome ficará em sigilo -, pudemos perceber que nestes documentos constam diretrizes sobre a organização da escola que visa oferecer condições adequadas que promovam o bem-estar das crianças, o seu desenvolvimento físico, motor, emocional, intelectual, moral e social, que ampliam suas experiências, bem como tentam estimulá-las no processo de conhecimento humano, da natureza e da sociedade, por meio do lúdico.

Essas propostas/atividades, já orientadas nos documentos escolares, têm como base interações e brincadeiras proporcionadas pelas professoras, em conjunto com as crianças, através da elaboração de planejamentos pelo Enfoque Emergente, que se traduz em pautar as situações de aprendizagem, conforme emergem, no convívio do professor com as crianças, entre as crianças, na/ entre a comunidade escolar. A partir do olhar cuidado e de uma escuta sensível (BARBIER, 2004) se pode vir a conhecer as necessidades e os interesses que os pequenos têm frente aos diferentes contextos que os rodeiam.

As crianças nos dão informações de várias maneiras diferentes. É importante garantir modos eficazes de apoiar as crian- 
ças a comunicar seus pontos de vista e para nós, aprender as muitas maneiras diferentes de as "escutar". Isto significa ouvir ativamente e observar as reações e respostas das crianças. Significa considerar a ação apropriada visível, que pode ser registrada, compartilhada, discutida e examinada com outras pessoas. (KINNEY; WHARTON, 2009, p. 23)

Tanto os Projetos, quanto a Proposta Pedagógica, o Regimento Escolar e os Planos de Estudos são elaborados de forma participativa pelos diferentes segmentos escolares (pais dos alunos, professores, direção, coordenação pedagógica, funcionários e comunidade escolar), sempre em tempo para serem repensados quando suas escritas destoarem das propostas trazidas para a Escola. Essa foi uma informação da Equipe Diretiva ao alcançar os documentos para a leitura e estudo.

É importante destacar que a elaboração destes documentos, procura sempre definir o que a Escola visa "com" as crianças e não "para" as crianças desde seu ingresso na Educação Infantil até sua transição para o Ensino Fundamental. Tais documentos citados levam em consideração a abordagem educacional de Reggio Emilia, a qual tem por princípio o Protagonismo Infantil, a escuta e a autonomia. Estes estudos também prezam pelo eixo das interações e brincadeiras, presentes nas Diretrizes Curriculares Nacionais para a Educação Infantil (BRASIL, 2010).

A avaliação/acompanhamento das aprendizagens das crianças é semestral e feita através de parecer descritivo, informando aos pais o desenvolvimento global do seu filho(a). O parecer escrito tem como propósito narrar as experiências das crianças e as formas como se dão os processos infantis, enquanto estão experenciando novas aprendizagens. Para tanto, salienta o Projeto Político Pedagógico (2015, p. 11) que "cabe ao profissional da Educação Infantil desenvolver a escuta e necessita estar atento a tudo o que acontece no espaço escolar".

O processo de avaliação é acompanhado por uma documentação sistemática onde as professoras realizam o registro das atividades/brincadeiras composta através de fotografias e relatos diários, feitos em seus cadernos de planejamento, pois são fundamentais para a constituição do portfólio das crianças. Para que se contemple uma observação rica do cotidiano infantil é importante que o professor disponibilize-se a perceber as necessidades das crianças, conforme seu crescimento, para ser falado a todos, 
principalmente aos pais, que entregam um tempo de crescimento de seus filhos à Escola, por necessidade de estarem distante, em seus empregos.

\section{O protagonismo infantil}

A Escola investigada se embasa para a elaboração e construção do seu planejamento diário a partir da concepção do Protagonismo Infantil. Esta inspiração vem dos estudos sobre o Enfoque Emergente, que é oriundo de uma perspectiva pedagógica surgida nas Escolas Municipais de Educação Infantil de Reggio Emilia, situada ao norte da Itália. Estas Escolas, que são referência em educação de crianças entre 0 a 6 anos de idade, são reconhecidas como as melhores Escolas de Educação Infantil no mundo, assim divulgado pela revista americana Newsweek, no ano de 1999 (EDWARDS, 1999).

$\mathrm{Na}$ Escola investigada ainda é recente a adaptação à abordagem do Protagonismo Infantil. Entretanto, a ideia de investir nos estudos e incluir esta proposta, tomou força quando foi oportunizada a edificação da Escola, após o município ser beneficiado com verbas para sua construção, pelo Ministério da Educação e Cultura (MEC), por meio do Programa da ProInfância - Programa Nacional de Reestruturação e Aquisição de Equipamentos para a Rede Escolar Pública de Educação Infantil. Este é um programa federal, de assistência financeira, que beneficia municípios para a construção de creches e pré-escolas e auxilia com equipamentos e mobiliário, promovendo o acesso à educação em Escolas públicas de Educação Infantil.

Após os primeiros estudos, que se dirigiam a eleger esta perspectiva pedagógica para a nova Escola, realizada a sua inauguração e início do seu funcionamento, com as outras duas Escolas de Educação Infantil do município e a Secretaria de Educação, deu-se início aos Ciclos Formativos do ProInfância. Muitos destes encontros de formação ocorreram na cidade de Santa Maria/RS, na Universidade Federal de Santa Maria (UFSM), e foram a base fundadora para o desafio a ser empreendido. A formação dos professores é uma parte muito importante nesse processo, uma vez que, para deixarem espaços de Protagonismo às crianças, se faz imprescindível que o professor sinta-se seguro de suas funções nos espaços pedagógicos. (DIAS, 2012) 
Os encontros para estas formações visavam ao assessoramento técnico e pedagógico às redes de ensino na implementação do ProInfância aos municípios da região central, norte e noroeste do estado do Rio Grande do Sul. Em muitos dos encontros proporcionados se realizaram estudos e acompanhamentos a projetos e atividades de Escolas de Educação Infantil, do Rio Grande do Sul. O objetivo era conhecer as práticas que já estavam sendo trabalhadas com a proposta do protagonismo infantil, pois acreditavam que esta, além de ser inovadora, auxiliaria a suprir as necessidades e desejos das crianças, garantindo-lhes uma aprendizagem mais significativa.

Para que fosse possível a implementação deste programa inovador nas Escolas, "[... foi preciso muita reflexão e estudos, juntamente com a comunidade escolar do município[...]", afirma a primeira professora investigada nesta análise. Pois, pensar em mudanças para o ensino não é uma tarefa fácil, necessita de muita dedicação e empenho, não só da instituição, mas também do apoio das famílias, que junto com a Escola almejam o melhor para seus filhos.

Mensalmente, através das reuniões pedagógicas dos professores, muito se discutia sobre a proposta. Estudo este que, segundo relatos da segunda professora investigada,

[...] faz dois anos apenas que a escola implementou; então ele é muito recente. Procuramos sempre discutí-lo nas reuniões pedagógicas, com o propósito de revermos as questões sistematizadas que antes eram trabalhadas, e de que forma almejamos daqui para frente, através da busca por estratégias, que venham ao encontro das necessidades dos nossos alunos. (PROFESSORA 2)

Apesar da proposta ser recente para a instituição, percebemos que esta foi muito bem aceita pela comunidade escolar. E na medida do possível, busca problematizá-la e pensá-la, como forma de avaliar o trabalho proposto. No início, comenta a diretora, a ideia de inovar a prática pareceu um tanto quanto assustadora para todos os profissionais da rede da Educação Infantil, pois estavam acostumados a trabalhar com as crianças de forma mais sistematizada, e parte dos profissionais ficavam se questionando se esta inovação poderia ou não dar certo (Diário de Campo).

Em mais anotações no Diário de Campo, seguem os apontamentos das conversas, com as professoras na escola, que levaram a perceber que: o passar dos dias proporcionaram um distancia- 
mento e tempo para se pensar sobre as práticas que aconteciam com as crianças e os professores foram encorajados a olhar para o projeto a partir de considerações desafiadoras para uma prática possível. Após analisar e muito discutir sobre os planejamentos que começavam a ser traçados a partir de outras concepções teóricas, perceberam que esta poderia ser sim, relevante para a Escola e principalmente para as crianças. Já para os pais, estas mudanças não foram tão assustadoras assim, pois muitos já estimulavam a autonomia de seus filhos, com sua pouca idade, em casa, a ensiná-los a tomarem banho e a trocarem suas roupas, sozinhos.

A mudança de proposta aconteceu e está se concretizando de forma minuciosa na EMEI, assim como foi em Reggio Emilia. Lá, a proposta surgiu após a Segunda Guerra Mundial, por volta de 1960, e também levou algum tempo para firmar-se até apresentar os resultados que os professores e pais acreditavam ser possível. A persistência é outro fator importante nesse processo: são novas aprendizagens e precisam de seu tempo para se mostrarem produtivas.

É nítido que ambas as Escolas possuem algo em comum: primeiro, por serem escolas públicas, e segundo, por buscarem forças e inspirações de trabalho juntamente com a comunidade escolar, crianças e seus familiares. Este elo que se cria com a Escola e a família das crianças, se torna uma espécie de ferramenta que viabiliza melhorar o ensino e o aprendizado nas Escolas, procurando, deste modo, proporcionar uma aprendizagem mais significativa para as crianças, através de uma pedagogia inovadora, inspirada no Protagonismo Infantil.

Esta proposta, de Reggio Emilia, engloba tanto o contexto no qual as crianças estão inseridas, quanto o espaço a ser pensado e planejado: envolve de modo geral os adultos que as rodeiam, respeitando-as, assim como seus interesses, em busca de uma perspectiva de trabalho nomeada projettazione. Entende-se por projettazione um planejamento flexível que é realizado pelos professores, a partir do que eles acreditam ser contribuinte para o crescimento das crianças, quando a aprendizagem, a partir de observações diárias realizadas frente ao interesse e necessidade das crianças (GANDINI; EDWARDS, 2002), evidencia-se ao se investir como orientação para as práticas em sala de aula. 
Esta proposta de ensino é constituída por 12 princípios, que são eles: o protagonismo infantil, a criança como possuidora de cem linguagens, o próprio projettazione, a escuta, a participação, a aprendizagem como processo subjetivo e grupal; a investigação, a documentação, a organização, o ambiente, espaço e relação, a formação profissional e a avaliação. (SILVA, 2011) Princípios esses que, somados, contribuem para a excelência da proposta das Escolas de Reggio Emilia, na Itália.

O protagonismo infantil, que consequentemente se torna um destacado princípio das práticas pedagógicas de Reggio Emilia, é definida por Horn (2004, p. 33), como "[...] uma proposta pedagógica que visou a descentração da figura do adulto na prática cotidiana, o que possibilitou mais autonomia por parte das crianças". Rinaldi (2012, p. 152) fala que esta é a forma que a criança é "capaz de associar e desassociar realidades possíveis, de elaborar metáforas e paradoxos criativos, de construir os próprios símbolos e códigos, enquanto aprende a decodificar os símbolos e códigos estabelecidos".

Pode-se dizer que o protagonismo infantil é uma concepção de infância, que apresenta a criança como um ser potente, capaz de criar formas e de se relacionar com o mundo a sua volta. É conceber a criança como ser que possui direitos e valores próprios e, com autonomia, participa do seu processo de ensino e aprendizagem. A terceira professora entrevistada traz sua compreensão do que seja o protagonismo infantil, depois dos estudos de formação:

Protagonismo Infantil é a criança, juntamente com a professora, colaborar e auxiliar na elaboração e execução de atividades/ brincadeiras, que são proporcionadas no decorrer das aulas, que visam saciar a curiosidade, anseios e necessidades dos alunos, frente aos conteúdos diversos, em busca de estratégias e planos que possam saná-las. (PROFESSORA 3)

A professora ainda se vê muito preocupada em "saciar a curiosidade" por meio de seu planejamento didático, ao encontrar "estratégias e planos que possam saná-las". Mais que isso, é deixar em aberto e provocar ainda mais curiosidades para que as próprias crianças saiam em busca de suas estratégias de aprendizagem. Que o planejamento seja conjunto entre professores e crianças, a professora está muito certa! 
Considerar uma criança Protagonista em sala de aula é permitir que ela se torne ativa, é respeitar as suas limitações e expressões, que são apresentadas através de suas infinitas linguagens simbólicas. É 1he dar voz e vez. Como já nos disse Malaguzzi (1999, p. 5), a criança

[...] tem cem linguagens em mãos, cem pensamentos, cem maneiras de pensar de brincar e de falar. Cem, sempre cem maneiras de ouvir, de surpreender, de amar. Cem alegrias para cantar e perceber. Cem mundos para descobrir. Cem mundos para inventar. Cem mundos para sonhar. A criança tem Cem linguagens (e mais cem, cem, cem) [...].

A passagem citada alerta para o potencial que a criança possui em seu espaço na escola e em sua vida social. A criança utiliza-se de suas "Cem Linguagens" para mostrar o que ela deseja e sente sobre algo, tanto sobre o espaço quanto em relação às pessoas que estão com ela. Para que a criança consiga se expressar é preciso que ela se sinta livre e inspirada. Por isso, cabe ao adulto proporcionar um ambiente adequado para que ela possa interagir e se manifestar, apresentando suas (infinitas) linguagens.

A aprendizagem é um processo extenso, no qual a criança passa por determinados momentos de experimentações, expressividade e criatividade. (RINALDI, 2012) Os professores são vistos como fios para uma trama: capazes de construir e constituir os entrelaçamentos e conexões da rede de relacionamentos entre ele e as crianças. É importante que o educador valorize o potencial e o poder que as crianças têm e propicie a confiança, para se expressarem e manifestarem seus desejos e anseios, proporcionando atividades/brincadeiras que despertem sua curiosidade e anseios frente aos diferentes assuntos e necessidades provenientes do seu cotidiano.

Um dos instrumentos utilizados em Reggio Emilia para perceber os interesses ou dificuldades demonstradas pelas crianças é detectado através da escuta, que segundo Rinaldi (2012, p.124), é definido como uma "metáfora da disponibilidade, da sensibilidade para escutar e ser escutado; escuta não só da audição, mas com todos os sentidos: visão, tato, olfato, paladar, orientação". Esta forma de escuta é importante na Educação Infantil porque nem sempre as crianças relatam sobre seus interesses e necessidades, 
mas demonstram através de suas expressões faciais, corporais, sons ou até mesmo através do seu próprio silêncio.

Saber interpretar os interesses e necessidades das crianças não é uma tarefa fácil, pois exige do professor atenção e um envolvimento muito grande, a fim de compreender os possíveis enfoques dados pelas crianças. A escuta se torna uma ferramenta eficaz ao professor que a utiliza como uma estratégia de ensino para alinhavar as hipóteses apresentadas pelas crianças e com as estratégias que ambos constroem. A "escuta pode ser um caminho para tentar compreender o contexto, sem fazer julgamentos a respeito dos interesses demonstrados pelas crianças". (SCHNEIDER, 2015, p. 71)

A escuta é um dos principais elementos utilizados pelas professoras da escola analisada - assim sugere o Projeto Político Pedagógico da instituição. Os professores acreditam que esta seja uma das atitudes eficazes na educação das crianças e colabora para melhor perceber as necessidades e interesses da turma, frente aos assuntos trazidos pelas crianças. "Escutando, investigando e documentando com as crianças, é uma forma de elaborar um projeto capaz de respeitar o protagonismo infantil apresentado por elas", enfatiza a quinta professora entrevistada.

É a partir desta escuta e registro, que as educadoras realizam diariamente, que elas deixam espaço para a criação: suas e das crianças. Estes são espaços nos quais emergem inúmeras estratégias de ensino, promotoras do protagonismo infantil: institui-se um espaço que oportuniza o "diálogo aberto com as crianças e a professora durante as atividades túdicas", afirma a quarta professora entrevistada. É através destes momentos menos rígidos de regras que as professoras colhem informações precisas para as suas práticas pedagógicas diárias.

As crianças sentem-se mais provocadas a se expressarem e apresentarem suas necessidades e interesses quando o ambiente no qual elas se encontram se tornam instigantes, convidando-as a entrar para viagens por elas imaginadas. O professor, então, é convidado também a contracenar em um mundo infantil, mas não infantilizado, pois está rico de argumentos pensados pelas crianças e acreditado pelos adultos. (COHN, 2005)

Em Reggio Emilia há uma conexão particular entre o tempo e o espaço e que funciona muito bem: as necessidades e ritmos das crianças moldam os arranjos dos espaços e o ambiente. 
(EDWARDS, 1999) Também o tempo disponibilizado abre-se a permitir que as crianças o explorem e o delineiem conforme seus ritmos. O espaço no qual as crianças se encontram é cuidado e flexível para mudanças porque se acredita que este seja o mote para aprendizagens significativamente lúdicas.

O ambiente escolar pode ser um espaço físico que estabelece afetos e relações interpessoais através da interação do professor com a criança. (FORNEIRO, 1998) Esse processo transmite sensações, evocam recordações, passando um ar de segurança, através dos odores, de suas formas, das cores e dos sons, que englobam a instituição. (HORN, 2004) O que a Escola pretende é tornar-se um estimulante espaço de aprendizagem, pelo acolhimento e organização que oferece.

Entretanto, com o intuito de favorecer o protagonismo infantil, não é suficiente um espaço de brincar (SCHNEIDER, 2015), mas todos são espaços potentes de ludicidade para a criança. A participação do professor que se mostra disponível em fazer aproximações, respeitando o pensamento de uma inteligência infantil é muito significativa. O fazer docente e a historicidade da turma se constituem pelas urdiduras entrelaçadas diariamente pelos bons encontros (ESPINOSA, 1992) que passam acontecer diariamente.

A Escola investigada também acredita que os espaços são fundamentais e construtores de conhecimentos significativos para as crianças. Apesar dos espaços do prédio da instituição não serem muito amplos, são organizados com muito cuidado e dedicação pelas educadoras que os planejam juntamente com as crianças. Semestralmente são confeccionados diferentes cantos interativos nas salas de aulas, que possibilitam, diariamente, as crianças brincarem e interagirem com seus colegas e professoras. Este cuidado tem-se a fim de que o aprendizado aconteça em meio à ludicidade e às experiências promovidas pelo convívio entre todos nesse espaço.

Não só o ambiente, mas a relação entre os professores, a família e a escola são componentes que fortalecem o processo educativo da criança, afirma Malaguzzi (1999). Expressar-se e acolher as expressões de todos mostra condições favoráveis a se experimentar em questionamentos, inquietações, críticas e sugestões. Assim, a relação que se estabelece nos espaços da Escola é harmonioso, onde todos possam se manifestar e sentirem-se acolhidos. 
A relação de acordo mútuo se faz presente na EMEI investigada, pois a Escola busca forças para a realização de seu trabalho, contando com a disponibilidade e apoio das famílias das crianças, que são coadjuvantes da proposta estabelecida. Todos, não medem esforços e, dentro do possível, procuram se fazer presentes na escola, atuando no cenário, como protagonistas nesta proposta, pois acreditam que esta perspectiva de ensino e aprendizado é a mais qualificada para seus filhos/as.

Durante as observações feitas para este estudo percebeu-se que a Escola acredita na proposta do protagonismo infantil, uma vez que favorece as crianças a serem coparticipantes de seu processo de ensino e aprendizado. Sentirem-se autoras de sua própria história, participando das combinações para seus encontros/aulas, oportunizadas com as professoras a elaborarem os projetos e planejamentos, torna-se encorajador a assumir o lugar de proponentes de desafios, que aparecem em seus curiosos questionamentos.

A fim de obter um sentido profundo e completo dos eventos e fenômenos nos quais estão inseridos e das experiências que merecem mais atenção, dão ênfase àquilo que lhes é de interesse e necessidades da turma. Além disso, é a partir de atividades sempre mais abertas que as crianças são encorajadas a tomarem as suas próprias decisões e a fazerem as suas escolhas, geralmente em consonância com os seus colegas, aumentando a sua confiança no que diz respeito ao aspecto intelectual, o que reforça a disposição de continuar aprendendo.

\section{Aprendizagens nunca finais}

Atualmente a Educação Infantil é reconhecida como um ambiente de socialização que abriga crianças pequenas da faixa etária de zero aos cinco anos e 11 meses de idade, sendo esta considerada a primeira etapa da Educação Básica. (BRASIL, 1996) Essa fase da educação visa proporcionar condições adequadas de desenvolvimento físico, psicológico, intelectual e social, promovendo a ampliação de experiências e conhecimentos.

Apesar do muito que se já se modificou o campo da Educação Infantil no sistema educacional brasileiro, cremos que a tendência da melhoria para o trabalho pedagógico nas Escolas deva, ainda mais, ampliar as condições físicas e metodológicas, com olhares direcionados para as crianças, para os professores e para a Escola. 
São estes os atores e os cenários importantes para que a educação se mostre significativa para a comunidade na qual se insere. Acreditamos que a Educação é que tem potentes condições de modificar os pensares e fazeres de um povo: que inicie, então, na infância.

A proposta voltada ao protagonismo infantil da Escola Municipal de Educação Infantil, situada no Vale do Taquari/RS/Brasil, ganhou vida após o município ser beneficiado pelo governo federal, com uma escola do programa Pro-Infância. Esta perspectiva metodológica foi aceita na Escola após algumas formações promovidas pela equipe de assessores/professores do Pro-Infância, oferecidas para as Equipes Diretivas e Secretarias de Educação das cidades que aceitaram o convite em conhecer e implantar essa proposta.

A ideia foi levada para o município e primeiramente foi estudada e discutida entre os profissionais da rede e em seguida foi compartilhada com a comunidade escolar, que passou a conhecê-la, acreditando ser possível. Continuar a buscar outros aspectos dentro desta proposta, discuti-los e avaliá-los, com intuito de melhorar a qualidade de ensino e aprendizagem do trabalho pedagógico, para Educação Infantil, continua sendo pauta da organização da escola.

A EMEI investigada embasou-se nos estudos já publicados das práticas das Escolas Municipais de Educação Infantil, de Reggio Emilia, situada ao norte da Itália. O trabalho que desenvolvem se destaca internacionalmente e, acima de tudo, respeita a integridade e autonomia da criança apresentada na sua relação com o adulto. O projeto relatado neste artigo surgiu há poucos anos no município e até hoje vem sendo discutido e analisado minuciosamente com a comunidade escolar, para melhor atender as demandas.

Assim como a Escola busca apoio nos estudos que divulgam, as práticas em Reggio Emilia, muito se detém nas Diretrizes Curriculares Nacionais para a Educação Infantil, buscando oferecer às crianças, durante as atividades lúdicas, a liberdade de expressão e a criatividade em suas diferentes manifestações artísticas e culturais, bem como respeitar a integridade entre elas e as educadoras, garantindo um espaço de convívio no qual goste de estar e queira voltar.

A busca pela ampliação de repertório de estudos pedagógicos fez com que as profissionais atuantes na Escola pensassem sobre suas atuações em sala de aula e analisassem sobre o méto- 
do utilizado até então: estava privando as crianças de buscarem conhecimentos que fossem do interesse delas, pois o que estava sendo trabalhado em sala de aula até o momento era organizado e sistematizado apenas pelos professores.

Assim, a proposta surge na Escola com a intenção de que as crianças participem de seu processo de ensino e de aprendizados, através do enfoque emergente, planejando juntamente com o professor as atividades/projetos/brincadeiras lúdicas para as práticas pedagógicas: querendo que sejam sempre inspiradas pelas necessidades e interesses que as crianças trazem dos diferentes contextos em que vivem.

Para que este projeto pudesse ganhar vida foi necessário contar com a força que os professores têm na Escola e motivou os profissionais da Educação a investirem na nova proposta. Depois, estendeu o convite aos pais que começaram a se mobilizar em uma rede de estudos para discutir e analisar o trabalho que está sendo oferecido na rede. É importante ressaltar que o trabalho que foi relatado continua sendo realizado e está se firmando gradualmente, pois a comunidade está dando um passo de cada vez. Então, o resultado deste trabalho não é conclusivo, uma vez que augura voltar a relatar mais conquistas neste processo.

Aproximar-se desse bonito trabalho realizado na Escola, pela via de uma análise que proporcionou conhecer mais da proposta de Reggio Emilia em uma Escola brasileira, pública, foi gratificante e uma rica experiência. Deixou-nos felizes em ter encontrado uma instituição de Educação Infantil que tivesse uma proposta de ensino diferenciada de tantas outras que parecem seguir padrões, indiferentes as culturas que as tecem. E que, acima de tudo, se preocupa com a integridade das crianças, proporcionando um ensino e aprendizado inovador, que vem ao encontro do que a comunidade escolar visa/espera de uma Escola de Educação Infantil.

\title{
Thinking about a Pedagogical Proposal in the School: Children and the Child Protagonism
}

\begin{abstract}
This article was made from the discussion about the Child Protagonism in a Public School, whose pedagogical proposal intensified from the challenge launched to its teachers. The research took as a scenario a Municipal School of Early Childhood Education, Vale do Taquari/RS/Basil, and analyzed a teaching proposal that has as its potential base, the valorization of the Child Protagonism. Methodologically, it was based on a qualitative conception, of ethnographic type, that was produced by participant observa-
\end{abstract}


tion. We approached children in the age group from 04 to 05 years of age and we showed the voice of five teachers, who answered about their practices and the elaboration of the daily planning, reporting on the emergence of the project on Child Protagonism, teaching and contributions of the proposal in children's learning. It was possible to verify in the study of this work that the methodology of this institution focused on the Emerging Approach is to prioritize the child as the protagonist of their learning, providing activities, projects, games, focused on their interests and needs in the different contexts in which they live. Teachers, parents, children and the school community aim, as far as possible, to discuss and analyze in detail the pedagogy offered by the School, in order to better meet the demand that is presented and to design the education in which they believe.

Keywords: Children's protagonism. Educational planning. Spaces in kindergarten. Early Childhood Education Teaching.

\section{Referências}

ABRAMOWICZ, A. O Direito das crianças à educação infantil. Proposições, Campinas, v. 14. n. 3, p. 13-24, set. /dez. 2003.

ANDRÉ, M. E. D. A. de. A pesquisa no cotidiano escolar. In: FAZENDA, I. (Org.) Metodologia da pesquisa educacional. São Paulo: Cortez, 1994.

ANGROSINO, M. Etnografia e observação participante. Tradução de José Fonseca. Porto Alegre: Artmed, 2009.

BARBIER, R. A pesquisa-ação. Tradução de Lucie Didio. Brasília, DF: Liber Livro, 2004.

BRASIL. Ministério da Educação. Secretaria de Educação Básica. Diretrizes Curriculares Nacionais para a Educação Infantil. Brasília, DF, 2010 .

BRASIL. Lei $n^{\circ} 9.394$ de 20 de dezembro de 1996. Estabelece as diretrizes e bases da educação nacional.1996. Disponível em: < http:// www.planalto.gov.br/ccivil_03/leis/19394.htm >. Acesso em: 28 nov. 2015.

COHN, C. Antropologia da criança. Rio de Janeiro: Jorge Zahar, 2005.

DIAS, R. de O. (Org.). Formação inventiva de professores. Rio de Janeiro: Lamparina, 2012.

DIAS, R. de O. Deslocamentos na formação de professores: aprendizagem de adultos, experiência e políticas cognitivas. Rio de Janeiro:

Lamparina, 2011.

EDWARDS, C. As Cem Linguagens da Criança: A abordagem de Reggio Emília na Educação da Primeira Infância. In: EDWARDS, C., GANDINI, L.; FORMAN, G. As cem linguagens da criança: a abordagem de Reggio Emilia na educação da primeira infância. Tradução de D. Batista. Porto Alegre: Artmed, 1999.

ESPINOSA, B. Ética. CARVALHO, J. de. Notas. Lisboa: Relógio d'Agua, 1992. 
FORNEIRO, L. I. A organização dos Espaços na Educação Infantil. In: ZABALZA, M. A. Qualidade em educação infantil. Tradução de B. A. Neves. Porto Alegre: Artmed, 1998.

GANDINI, L.; EDWARDS, C. Bambini:a abordagem italiana à educação infantil. Tradução de D. Etcheverry Burguño. Porto Alegre: Artmed, 2002.

GRAVATÁ, A. Volta ao mundo em 13 escolas. São Paulo: Fundação Telefônica: A. G., 2013.

HORN, M. da G. S. Sabores, cores, sons e aromas: a organização dos espaços na educação infantil. Porto Alegre: Artmed, 2004.

KINNEY, L. WHARTON, P. Tornando visivel a aprendizagem das crianças. Porto Alegre: Artmed, 2009.

KUHLMANN, M. J. Infância e educação infantil: uma abordagem histórica. Porto Alegre: Mediação, 1998.

LÜDKE, M.; ANDRÉ, M. E. D. A. de. Pesquisa em educação: abordagens qualitativas. São Paulo: EPU, 2013.

MALAGUZZI, L. Histórias, idéias e filosofia básica. In: EDWARDS, C. As cem linguagens da criança: a abordagem de Reggio Emilia na Educação da Primeira Infância. Tradução de D. Batista. Porto Alegre: Artmed, 1999.

RINALDI, C. Diálogos com Reggio Emilia: escutar, investigar e aprender. Tradução de V. Cury. São Paulo: Paz e Terra, 2012.

SCHNEIDER, M. C. O protagonismo infantil e as estratégias de ensino que o favorecem em uma turma de educação infantil. 2015. 147 p. Dissertação (Mestrado em Ensino) - Centro Universitário UNIVATES, Lajeado, 2015.

SILVA, J. S. da. O planejamento no enfoque emergente: uma experiência no $1^{\circ}$ Ano do Ensino Fundamental de Nove Anos. 2011. 237 f. Tese (Doutorado em Educação) - Faculdade de Educação. Universidade Federal do Rio Grande do Sul, Porto Alegre, 2011.

Filmografia:

Sementes do nosso quintal. Direção de Fernanda Heinz Figueiredo. Documentário. São Paulo: Espaço Filmes, 2014.

Quando sinto que já sei. Direção de Antonio Sagrado, Raul Perez e Anderson Lima. Documentário. São Paulo: Despertar Filmes, 2014. 
